\title{
Synthesis, characterization of cesium and cobalt substituted wells-Dawson heteropolyoxotungstates salts and their photocatalytic applications
}

\author{
A. Balaska ${ }^{1}$, R. Belghiche ${ }^{2}$, M.-H. Samar ${ }^{2}$, T. Chouchane $^{2}$ and R. Haseneder ${ }^{3}$ \\ ${ }^{1}$ Centre national de recherche en soudage et contrôle-C.S.C, Unité de recherche appliquée en sidérurgie \\ métallurgie (U.R.A.S.M/C.S.C Annaba), BP. 196, 23000 Annaba, Algérie \\ ${ }^{2}$ Laboratoire de génie de l'environnement, département génie des procèdes, université Badji Mokhtar-Annaba, \\ BP. 12, 23000 Annaba, \\ ${ }^{3}$ Algérie Department of Environmental Processes Engineering, Freiberg University of Mining and Technology, \\ Leipziger Strasse 28, 09596 Freiberg, Germany
}

\begin{abstract}
Heteropoly compounds in the solid state are ionic crystals (sometimes amorphous) consisting of large polyanions, cations, water of crystallization, and other molecules. Heteropolyacids (HPAs) have several advantages as catalysts. On the one hand, they have a very strong Brønsted acidity, especially the cobalt and cesium salts; on the other hand they are exhibiting fast reversible multielectron redox transformations under mild conditions. The cobalt and cesium salts of wellsDawson HPAs were synthesized and characterized using elemental analysis and spectroscopic techniques $\left({ }^{31}\right.$ P-NMR, FT-IR). The wells-Dawson anions possess the ability to accept or release electrons through an external potential or upon exposure to UV radiation (photochemical reactions). The catalytic tests of these salts were investigated on phenol degradation where the UV photodegradation of acidified aqueous solutions $(\mathrm{pH}=2)$ were studied in a batch photoreactor under ambient temperature and continuous circulation of phenol solution. The results reveal high catalytic activity for two HPAs, the best catalyst is the salt of cesium; where the presence of cesium improves significantly both the photcatalytic activity and the selectivity to oxalic acid.
\end{abstract}

\section{INTRODUCTION}

Solid state photochemical studies have recently become important due to their relevance in catalysis technologies.

The chemical, photochemical and electrochemical properties of heteropolyanions have been subject of great interest primarily due to their wide ranging catalytic applications [1]. Particular attention has been given to redox property can be tuned by replacing protons or by substituting framework transition-metal atoms with different metals [2].

The first report of what we refer now to a POM dates back to Berzelius (1826) [3] who described the yellow precipitate that is produced when ammonium molybdate is added in excess to phosphoric acid and which is now known as $(\mathrm{NH} 4)_{3}\left[\mathrm{PMo}_{12} \mathrm{O}_{40}\right]_{\mathrm{aq}}$, with the co-called 12:1 ratio.

Heteropolycompounds generally, constitute a large category of well-defined metal oxygen cluster anions, formed by condensation of mainly tungstates and/or molybdates with or without participation of a variety of other elements [1,4-6].

Together with the Keggin anion, the Wells-Dawson molecule is, probably, the second heteropolyanion in popularity. Heteropolyanions Dawson - type [7] formed by the connection of metal-oxygen polyhedral building blocks via covalent bonding.

Wells-Dawson polyoxometalates (POMs) have hierarchical structure; Fig. 1 shown three structures [8]. The primary structure is the structure of heteropolyanion itself, i.e. the metal oxide cluster. The secondary structure is the three-dimensional arrangement consisting of polyanions, counter cations and additional molecules.

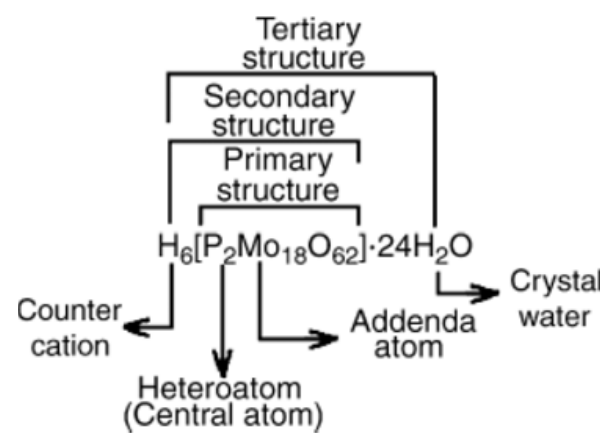

Figure 1. Primary, secondary and tertiary structure of WellsDawson POM.

The tertiary structure represents the manner in which the secondary structure assembles into solid particles and relates to properties such as particle size, surface area and pore structure (substituted heteropolyacid -HPA- for example) [9].

Heteropolyacids (HPAs) and transition metalsubstituted heteropolyacids have more attracted interest as catalysts in many reactions than heteropolyanion salts because of their, their stronger Brønsted acidity, thermal, chemical stability and the possibilities for modification $[10,11]$. These are come to be widely used as homogeneous and heterogeneous acidic oxidative catalysts by virtue of their unique physicochemical properties [12].

The HPA-salts substituted by large cations such as $\mathrm{Cs}^{+}$ are insoluble in water and exhibit low absorptivity for polar molecules. Low solubility is due to the low energy of solvation of large cations [13]. 
Because their insolubility in aqueous medium; cesiumsubstituted HPA Dawson-type was synthesized and characterized and used as a heterogeneous catalyst. Besides, cobalt-substituted HPA was also prepared and characterized and used as a homogeneous photocatalyst.

Catalytic tests of several prepared HPAs were examined by photodegradation process in phenolic aqueous solution.

\section{EXPERIMENTAL}

\subsection{Chemicals}

The Lacunary derivatives of the Wells-Dawson tungstophosphate anion, $\alpha-\left[\mathrm{P}_{2} \mathrm{~W}_{18} \mathrm{O} 62\right]^{6-}$, have been thoroughly investigated by Contant and Ciabrini [14], who were the first to isolate both possible monovacant lacunary species, now identified as $\alpha_{1}$ and $\alpha_{2}-\left[\mathrm{P}_{2} \mathrm{~W}_{17} \mathrm{O}_{61}\right]^{10-}$, together with the tri- and hexavacant species $\alpha-\left[\mathrm{P}_{2} \mathrm{~W}_{15} \mathrm{O}_{56}\right]^{12-}$ and $\alpha-\left[\mathrm{H}_{2} \mathrm{P}_{2} \mathrm{~W}_{12} \mathrm{O}_{48}\right]^{12-}\left(\mathrm{P}_{2} \mathrm{~W}_{12}\right)$. All of these lacunary anions, except $\mathrm{P}_{2} \mathrm{~W}_{12}$, have been shown to react with transition metal $[15,16]$.

Pure water was used throughout. It was obtained by passage through a Milli-RO4 unit and subsequently through a Millipore $Q$ water purification set. All the chemicals were of high-purity grade and were used as received. $\mathrm{HCl}, \mathrm{Na}_{2} \mathrm{SO}_{4}, \mathrm{Li}_{2} \mathrm{SO}_{4}, \mathrm{CH}_{3} \mathrm{CO}_{2} \mathrm{H}, \mathrm{CH}_{2} \mathrm{ClCO}_{2} \mathrm{H}$, $\mathrm{CH}_{3} \mathrm{CO}_{2} \mathrm{Na}, \mathrm{H}_{3} \mathrm{PO}_{4}, \mathrm{NaH}_{2} \mathrm{PO}_{4}, \mathrm{H}_{3} \mathrm{BO}_{3}$ (Prolabo), and phenol, Tris-(hydroxymethyl)-methylamine, ethyl ether, diether, $\mathrm{CsCl}, \mathrm{Co}\left(\mathrm{NO}_{3}\right)_{2}$, acetonitrile and reagents used to identify intermediate products of degradation (Aldrich) were commercial products. Other $\mathrm{pH}$ values were adjusted by addition of $\mathrm{H}_{2} \mathrm{SO}_{4}$ or $\mathrm{NaOH}$ (Prolabo).

\subsection{Synthesis of substituted Wells Dawson HPAs}

The synthesis of $\mathrm{H}_{6} \mathrm{P}_{2} \mathrm{~W}_{18} \mathrm{O}_{62} . n \mathrm{H}_{2} \mathrm{O}$ (HPAD) has been carried out in two steps. The first step consisted of the preparation of the potassium salt $\alpha \mathrm{K}_{6} \mathrm{P}_{2} \mathrm{~W}_{18} \mathrm{O}_{62} . n \mathrm{H}_{2} \mathrm{O}$ according to literature methods [17]. In the second stage, the HPAD was obtained through the "etherate method" according to literature methods described in [18], where the potassium salt was transformed into the acid by dissolving it in a small amount of water and gradually adding concentrated hydrochloric acid (37\%). The released free HPA was extracted with ethyl ether. The oily etherate separated from the solution was subsequently decomposed on a hot water bath. The remaining acid was dried at $100{ }^{\circ} \mathrm{C}$ and placed in a vacuum desiccator until crystallization. The water content of the samples was determined by standard methods [19,20], which showed that the composition of the sample corresponded to $\mathrm{H}_{6} \mathrm{P}_{2} \mathrm{~W}_{18} \mathrm{O}_{62} .14 \mathrm{H}_{2} \mathrm{O}$.

Cesium-substituted HPA salt was obtained by neutralizing the adequate quantities of $\mathrm{H}_{6} \mathrm{P}_{2} \mathrm{~W}_{18} \mathrm{O}_{62}(0,21 M)$ with the appropriate portions of cesium chloride solution $\mathrm{CsCl}$ $(1,08 \mathrm{M})$ :

$\mathrm{H}_{6} \mathrm{P}_{2} \mathrm{~W}_{18} \mathrm{O}_{62}+x \mathrm{CsCl} \rightarrow\left(\mathrm{Cs}_{x} \mathrm{H}_{6-x} \mathrm{P}_{2} \mathrm{~W}_{18} \mathrm{O}_{62} \downarrow+x \mathrm{HCl}\right.$
$\mathrm{CsCl}$ salt was slowly added $\left(1 \mathrm{~cm}^{3}\right.$ per $\left.4 \mathrm{~min}\right)$ to the solution of $\mathrm{H}_{6} \mathrm{P}_{2} \mathrm{~W}_{18} \mathrm{O}_{62}$ at vigorous mixing at room temperature. Cesium salt precipitated in form of milky suspension. It was kept at room temperature and subsequently evaporated together with supernatant liquid on a water bath at $45-50{ }^{\circ} \mathrm{C}$ [21].

Cobalt-containing HPA was obtained by the ion exchange of HPAD with the dissolved cobalt cations $\mathrm{Co}^{2+}\left(\mathrm{Co}\left(\mathrm{NO}_{3}\right)_{2}, 1 \mathrm{M}\right)$, in aqueous medium, is carried out according to the following reactional schema:

$$
\begin{gathered}
\mathrm{H}_{6} \mathrm{P}_{2} \mathrm{~W}_{18} \mathrm{O}_{62}+x \mathrm{Co}\left(\mathrm{NO}_{3}\right)_{2} \rightarrow \mathrm{Co}_{x} \mathrm{H}_{6-2 x} \mathrm{P}_{2} \mathrm{~W}_{18} \mathrm{O}_{62} \\
+2 x \mathrm{HNO}_{3} .
\end{gathered}
$$

All salts were recrystallized twice, dried in a vacuum and kept at room temperature in desiccators.

\subsection{Characterisation of catalysts}

All HPAs were characterized by, elementary analysis (EBSD Philips XL30), spectroscopic method (IR, ${ }^{31} \mathrm{P}$ NMR, ${ }^{31} \mathrm{P}$ MAS.

${ }^{31} \mathrm{P}$ NMR analysis was performed with Bruker MSL 300 equipment operating at $121.496 \mathrm{MHz}$. A sample holder of $5 \mathrm{~mm}$ diameter and $17 \mathrm{~mm}$ height was used. The spin rate was $2.1 \mathrm{kHz}$ and several hundreds of pulse responses were collected. The reference used was external $85 \% \mathrm{H}_{3} \mathrm{PO}_{4} / \mathrm{D}_{2} \mathrm{O}$ for liquid and solid NMR analyses.

Infrared analysis was performed with FT-IR Bruker IFS 66 equipment under ambient conditions solid samples were diluted with $\mathrm{KBr}$ and pressed into thin wafers. The solutions of the Dawson salt at different $\mathrm{pH}$ values were analysed by placing a drop of the liquid between $\mathrm{KBr}$ plates.

Specific surface area measurements for cesium HPA was measured using Quantachrome Nova 2000 apparatus. Samples were pretreated at $110^{\circ} \mathrm{C}$ for $3 \mathrm{~h}$ in vacuum.

\subsection{Catalytic tests}

Photocatalytic degradation of aqueous dioxygen saturated solutions of phenol $\left(1.06 \times 10^{-3} \mathrm{M}\right)$ under ultraviolet irradiation ook place effectively in the presence of catalysts. All degradation experiments were conducted in a Pyrex cylindrical photoreactor with 0.851 of volume was used in the experiments, in which a high-pressure mercury lamp (Heraeus, TQ $718700 \mathrm{~W}$ ) lamp emitting UV light at $254 \mathrm{~nm}$ was positioned at the centre of the cylindrical vessel and surrounded by a circulating water jacket to control the temperature at $25 \pm 1{ }^{\circ} \mathrm{C}$ during reaction.

Photodegradation of phenol were monitored using, an high performance liquid chromatography (HPLC) apparatus consisted of a water (Merck-Hitachi) model L-6200 A pump associated with a waters Model 6200 gradient controller, a reversed phase $\mathrm{C}_{18}$ analytical column $(250 \mathrm{~mm} \times 4.6 \mathrm{~mm}$ ID, $5 \mu \mathrm{m})$, and UV/Vis detector (L-4250. 190-700 nm) mark. A mixture of acetonitrile $(70 \%, v / v)$ and deionized water flowing at a rate of $1 \mathrm{~mL} / \mathrm{min}$ was used as the mobile phase. Aliquots of $20 \mu 1$ were injected onto a reversed phase $\mathrm{C}_{18}$ column and analyzed at a wavelength of $254 \mathrm{~nm}$ by UV/Vis detector. 
Table 1. Summary of elemental analysis of catalysts.

\begin{tabular}{llllll}
\hline$H P A$ & \multicolumn{7}{c}{$W(\%)$} \\
\hline & $\mathrm{W}$ & $\mathrm{P}$ & $\mathrm{Co}$ & $\mathrm{Cs}$ & $\mathrm{H}_{2} \mathrm{O}$ \\
HPD & 74.15 & 1.42 & - & - & 5.51 \\
Co-salt & 70.32 & 1.28 & 3.11 & - & 6.1 \\
Cs-salt & 67.1 & 1.36 & - & 6.92 & 6.95 \\
\hline
\end{tabular}

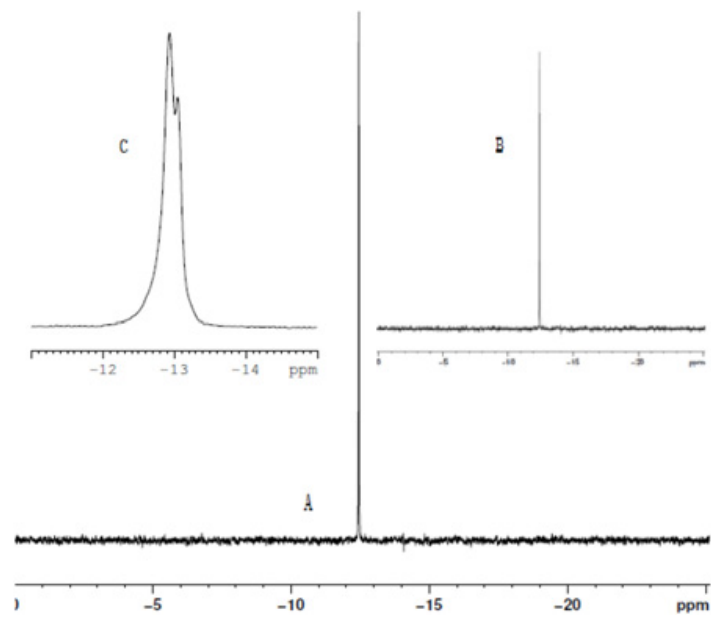

Figure 2. ${ }^{31} \mathrm{PNMR}$ spectrum of: A) $\mathrm{H}_{6} \mathrm{P}_{2} \mathrm{~W}_{18} \mathrm{O}_{62} \cdot 14 \mathrm{H}_{2} \mathrm{O}$, B) $\mathrm{Co}_{2.5} \mathrm{H}_{3.5} \mathrm{P}_{2} \mathrm{~W}_{18} \mathrm{O}_{62}$ and ${ }^{31} \mathrm{PMAS}$ spectrum of: C) $\mathrm{Cs}_{2.5} \mathrm{H}_{3.5} \mathrm{~W}_{18} \mathrm{O}_{62}$ samples.

\section{RESULTS AND DISCUSSION}

\subsection{Characterization}

Elemental analysis results of all HPAs were shown in Table 1. The total weight loss corresponded to $14 \mathrm{H}_{2} \mathrm{O}$ per mole of acid, $19 \mathrm{H}_{2} \mathrm{O}$ for $\mathrm{Cs}_{2.5}$-salt and $16 \mathrm{H}_{2} \mathrm{O}$ for $\mathrm{Co}_{2.5}$-salt. The formulas of all HPAs were as follows: $\mathrm{H}_{6} \mathrm{P}_{2} \mathrm{~W}_{18} \mathrm{O}_{62} .14 \mathrm{H}_{2} \mathrm{O}, \mathrm{Co}_{2.5} \mathrm{H}_{3.5} \mathrm{P}_{2} \mathrm{~W}_{18} \mathrm{O}_{62} .16 \mathrm{H}_{2} \mathrm{O}$ and $\mathrm{Cs}_{2.5} \mathrm{H}_{3.5} \mathrm{~W}_{18} \mathrm{O}_{62} .19 \mathrm{H}_{2} \mathrm{O}$.

The BET specific surface area calculated from the $\mathrm{N}_{2}$ sorption isotherm at $77 \mathrm{~K}$ determined for the dehydrated sample of $\mathrm{Cs}_{2.5}$-salt was equal to $1.35 \mathrm{~m}^{2} \mathrm{~g}^{-1}$, which has been use as heterogeneous catalyst in this work.

Figure 2 shows the ${ }^{31} \mathrm{PNMR}$ spectrum of sample $\mathrm{H}_{6} \mathrm{P}_{2} \mathrm{~W}_{18} \mathrm{O}_{62} .14 \mathrm{H}_{2} \mathrm{O}$. The peak at $-12.44 \mathrm{ppm}$ is characteristic of $\alpha$ isomer. This result was exhibited one pick due to the absence of the $\beta$ isomer absence of a peak and indicated that no contamination with phosphoric acid or phosphates was present. For $\mathrm{Co}_{2.5} \mathrm{H}_{3.5} \mathrm{P}_{2} \mathrm{~W}_{18} \mathrm{O}_{62} \mathrm{HPA}$, we obtained a similar result. For $\mathrm{Cs}_{2.5} \mathrm{H}_{3.5} \mathrm{~W}_{18} \mathrm{O}_{62}$ peaks at -12.93 and -13.05 were the main peaks, demonstrating that $\mathrm{Cs}_{2.5}$-salt mainly consists of polyanions with three protons $\left(\mathrm{Cs}_{3} \mathrm{H}_{3} \mathrm{~W}_{18} \mathrm{O}_{62} ;-12.93 \mathrm{ppm}\right)$ at bridging oxygen and those with four protons $\left(\mathrm{Cs}_{2} \mathrm{H}_{4} \mathrm{~W}_{18} \mathrm{O}_{62} ;-13.05 \mathrm{ppm}\right)$.

The IR absorption frequencies of the four compounds are shown in Table Fig. 3, the Ft-IR spectra of the three HPAs are basically the same, the three characteristic peaks in a range of $500-1100 \mathrm{~cm}^{-1}$ indicate that the four compounds possess Dawson structure. Compared with that of non-substituted phosphomolybdic heteropoly acid $\left(\mathrm{H}_{6} \mathrm{P}_{2} \mathrm{~W}_{18} \mathrm{O}_{62}\right)$, the IR spectrum has a relatively small part of transformation except key bridge vibration.

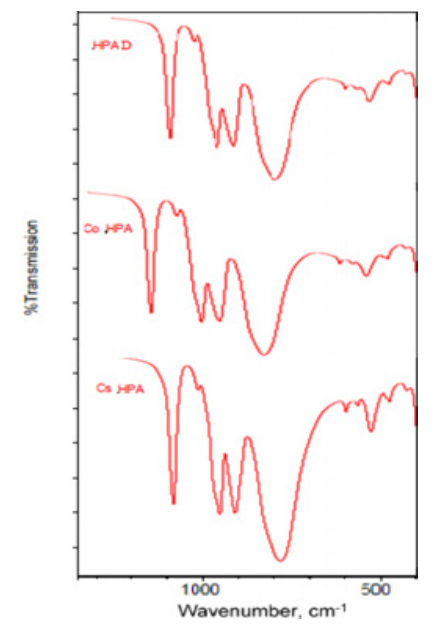

Figure 3. FT-IR patterns of HPAD $\left(\mathrm{H}_{6} \mathrm{P}_{2} \mathrm{~W}_{18} \mathrm{O}_{62}\right)$, Co HPA $\left(\mathrm{Co}_{2.5} \mathrm{H}_{3.5} \mathrm{P}_{2} \mathrm{~W}_{18} \mathrm{O}_{62}\right)$ and Cs HPA $\left(\mathrm{Cs}_{2.5} \mathrm{H}_{3.5} \mathrm{~W}_{18} \mathrm{O}_{62}\right)$.

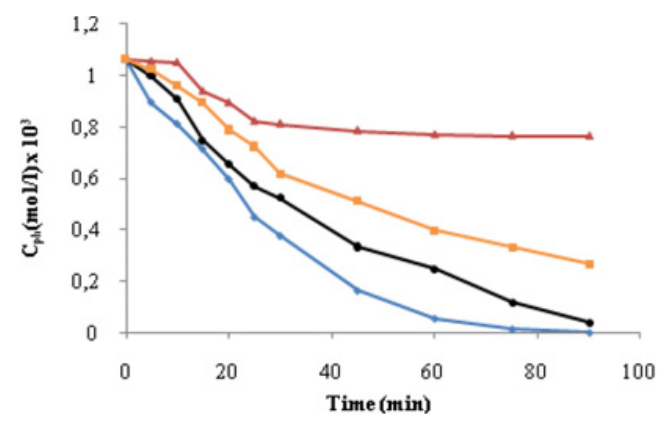

Figure 4. Photodegradation of oxygenated aqueous solution of phenol $\left(1.06 \times 10^{-3} \mathrm{M}\right)$ in the absence of HPA $(\boldsymbol{\Delta})$, presence $8 \times 10^{-4} \mathrm{M}(\boldsymbol{\square})$ of $\mathrm{H}_{6} \mathrm{P}_{2} \mathrm{~W}_{18} \mathrm{O}_{62} ;(\bullet)$ of $\mathrm{Co}_{2.5} \mathrm{H}_{3.5} \mathrm{P}_{2} \mathrm{~W}_{18} \mathrm{O}_{62}$ and ४) $0.7 \mathrm{~g}$ of $\mathrm{Cs}_{2.5} \mathrm{H}_{3.5} \mathrm{~W}_{18} \mathrm{O}_{62}$ at $\mathrm{pH} 2$.

\subsection{Catalytic activity}

Figure 4 shows a typical catalytic run. Three catalysts are compared: HPAD, Cs-substituted HPA and Co-substituted HPA indicating higher photocatalytic activity of cesium salt in phenol degradation. It is seen that degradation yield was $100 \%$ over $1.5 \mathrm{~h}$.

A question may be asked as to how these surface transformations influence the photcatalytic properties of the Cs-HPAs. In order to answer this question, we could be tested Cs-HPAs catalyst, using a series of Cs-HPA and with different loadings, whereas the Co-HPA loading has been also investigated. Results of these experiments are shown in Fig. 5 and Fig. 6.

This HPA has a high photocatalytic activity, when we have used this heterogeneous catalyst, we note that the optimum load of heterogeneous (Cs-substituted HPA) catalyst was $0.9 \mathrm{~g}$ and $10^{-2} \mathrm{M}$ for homogeneous catalyst (Co-substituted HPA).

Study-state catalytic performance data obtained after the time of degradation, where we have used the acid strength of; $\mathrm{Cs}_{2.5} \mathrm{H}_{3.5} \mathrm{~W}_{18} \mathrm{O}_{62}$ as heterogeneous catalyst and $\mathrm{Co}_{2.5} \mathrm{H}_{3.5} \mathrm{~W}_{18} \mathrm{O}_{62}$ as homogeneous catalyst, the results shown a high catalytic activity for Cs-HPA with $100 \%$ yield of phenol degradation during $25 \mathrm{~min}$ and $45 \mathrm{~min}$ for Co-salt. 


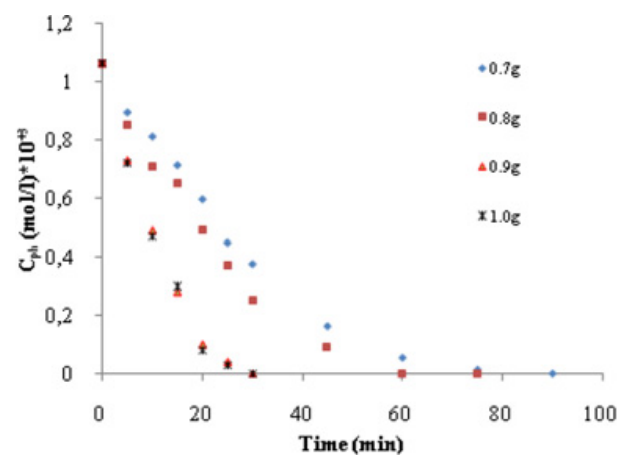

Figure 5. Effect of load of $\mathrm{Cs}_{2.5} \mathrm{H}_{3.5} \mathrm{~W}_{18} \mathrm{O}_{62}$ at $\mathrm{pH} 2$ and $1.06 \times 10^{-3} \mathrm{M}$ of phenol initial concentration.

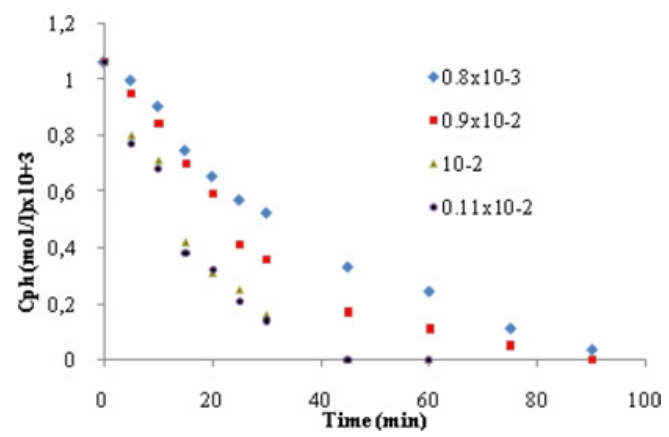

Figure 6. Effect of load of $\mathrm{Co}_{2.5} \mathrm{H}_{3.5} \mathrm{~W}_{18} \mathrm{O}_{62}$ at $\mathrm{pH} 2$ and $1.06 \times$ $10^{-3} \mathrm{M}$ of phenol initial concentration.

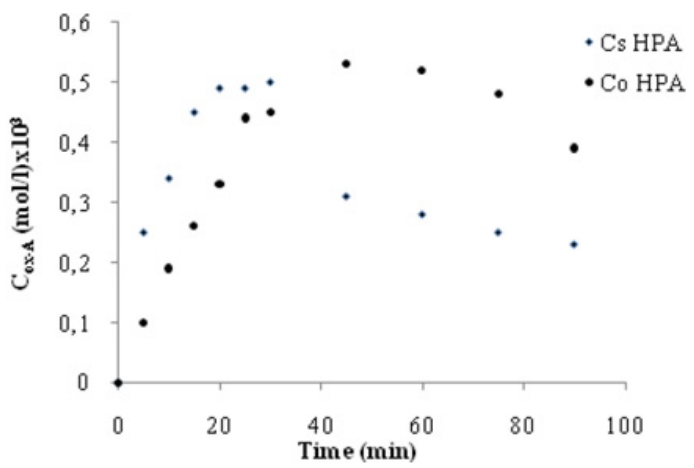

Figure 7. Formation of oxalic acid upon photplysis of oxygenated aqueous solution of phenol $\left(1.06 \times 10^{-3} \mathrm{M}\right)$ in the absence presence $(\bullet) 8 \times 10^{-4} \mathrm{M}$ of $\mathrm{Co}_{2.5} \mathrm{H}_{3.5} \mathrm{P}_{2} \mathrm{~W}_{18} \mathrm{O}_{62}$ and $(\bullet$ $0.9 \mathrm{~g}$ of $\mathrm{Cs}_{2.5} \mathrm{H}_{3.5} \mathrm{~W}_{18} \mathrm{O}_{62}$ at $\mathrm{pH} 2$.

Upon absorbance of UV or near-visible light, HPA catalyst is excited and serves as a strong oxidant to oxidize a great variety of organic substances either indirectly via ${ }^{\bullet} \mathrm{OH}$ radicals-mediated oxidations, where the photocatalytic degradation of organic pollutants (substrate), in the presence of POM, the oxidation is supposed to be performed by highly oxidizing ${ }^{\circ} \mathrm{OH}$ radicals produced indirectly i.e., substrates react with ${ }^{\bullet} \mathrm{OH}$ radicals resulting from reaction of excited $\mathrm{POM}$ with water molecules, [23].

Also, Dioxygen is a very effective oxidant for reduced HPA, thus its main action is the regeneration of the catalyst and may participate further in additive oxidative processes $[23,24]$.
The only intermediate product that could be identified was oxalic acid after photolysis usin Cs HPA andd Co HPA Fig. 7). For HPAD, we have detected also acetic acid and some aromatic compounds such: hydroquinone.

\section{CONCLUSION}

A synthesis was performed, giving a remarkably high yield of pure and their heteropolyanion (primary structure), with only one intermediate precipitation step, an appropriate but optimal excess of P over W. Elemental analysis, FTIR spectroscopy, ${ }^{31} \mathrm{P}$ NMR and ${ }^{31} \mathrm{P}$ Mas spectroscopy were used to demonstrate unambiguously that the isolated product in the optimal conditions of substituted HPAs, where the formulas of synthesized were as follows: $\mathrm{H}_{6} \mathrm{P}_{2} \mathrm{~W}_{18} \mathrm{O}_{62} .14 \mathrm{H}_{2} \mathrm{O}, \mathrm{Co}_{2.5} \mathrm{H}_{3.5} \mathrm{P}_{2} \mathrm{~W}_{18} \mathrm{O}_{62} .16 \mathrm{H}_{2} \mathrm{O}$ and $\mathrm{Cs}_{2.5} \mathrm{H}_{3.5} \mathrm{~W}_{18} \mathrm{O}_{62} .19 \mathrm{H}_{2} \mathrm{O}$. specific surface area of heterogeneous catalyst, $\mathrm{Cs}_{2.5} \mathrm{H}_{3.5} \mathrm{~W}_{18} \mathrm{O}_{62} .19 \mathrm{H}_{2} \mathrm{O}$ was obtained $1.35 \mathrm{~g} . \mathrm{m}^{-2}$.

The photocatalytic degradation phenol in the presence of $\mathrm{Cs}_{2.5} \mathrm{H}_{3.5} \mathrm{~W}_{18} \mathrm{O}_{62} .19 \mathrm{H}_{2} \mathrm{O}$ and $\mathrm{Co}_{2.5} \mathrm{H}_{3.5} \mathrm{~W}_{18} \mathrm{O}_{62} .16 \mathrm{H}_{2} \mathrm{O}$ leads to an oxalic acid as intermediate products with a yield $100 \%$ of phenol degradation. In addition, aromatic and aliphatic intermediate products were detected in the presence of $\mathrm{H}_{6} \mathrm{P}_{2} \mathrm{~W}_{18} \mathrm{O}_{62} .14 \mathrm{H}_{2} \mathrm{O}$ catalyst.

Wells-Dawson type substituted cesium salts and cobalt are active catalysts in photodegradation process. Their activity related to the HPA leading and kind of catalysis.

\section{References}

[1] M.T. Pope, Heteropoly and Isopoly Oxometallates, Springer, Berlin (1983).

[2] D.R. Park, J.C. Jung, J. Lee, S.H. Song, H. Kim, J.H. Song and I.K. Song, Catal. Lett 126 (3-4), 308-312 (2008).

[3] J.J. Berzelius, Poggend. Ann. Phys. Chem 6, 369 (1826).

[4] L.C.W. Baker and D.C. Glick, Chem. Rev 98 (16), 3 (1998).

[5] P. Kormali, A. Troupis, T. Triantis, A. Hiskia and E. Papaconstantinou, Catal Today 124 (1-3), 149-155 (2007).

[6] J.M. Pigga. PhD thesis, State of Counter-cations in Polyoxometalate Solutions, Lehigh University, Bennsylvania, U.S.A, 3 (2010).

[7] B. Dawson, Acta Crystallogr 6, 113 (1953).

[8] E.B.Wang, C.W. Hu and L. Xu, Concise Polyoxometalates, first Ed., Chemical Industry, Beijing, 5 (1998).

[9] G. Li, Y. Ding, J. Wang, X. Wang and J. Suo, J. Mol. Catal A-Chem 262, 67-76 (2007).

[10] R. Neumann and H. Miller, H. , J. Chem. Soc., Chem. Commun 22, 2277-2278 (1995).

[11] W. Kanjina and W. Trakarnpruk, J. Met Mate. Miner 20 (2), 29 (2010).

[12] I.V. Kozhevnikov, Russian Chemical Reviews, 56 (9), 811 (1987). 
[13] T. Okuhara, N. Mizuno, and M. Misono, "Catalytic Chemistry of Heteropoly Compounds", Adv. Catal. 41, 124 (1996).

[14] R. Contant and P.J. Ciabrini, J. Chem. Res., Synop, 222 (1977).

[15] R.G. Finke, M.W. Droege and P.J. Domaille, Inorg. Chem 26, 3886 (1987).

[16] A. Ostuni, M.T. Pope, C. R. Acad. Sci. Paris, Série IIc, Chimie: Chemistry 3, 199-204 (2000).

[17] D.K. Lyon, W.K. Miller, T. Novet, P.J. Domaille, E. Evitt, D.V.C. Jonson and R.G. Finke, J. Am. Chem. Soc 113 (19), 7209-7221 (1991).

[18] G.T. Baronetti, L.E. Briand, U. Sedran and H.J. Thomas, Appl. Catal. A-Gen 172 (2), 265-272 (1998).
[19] J. Poźniczek, A. Lubańska, D. Mucha and A. Bielański, J. Mol. Catal. A-Chem 257, 99-104 (2006).

[20] J. Poźniczek, A.M. Ilnicka, A. Lubańska and A. Bielański, J. Mol. Catal. A-Chem 286, 52-60 (2005).

[21] T. Okuhara, T. Nishimura, H. Watanabe and $M$. Misono, J. Mol. Catal 74, 247-256 (1992).

[22] C.J. Lin, S.L. Wang, P.M. Huang, Y.M. Tzou, J.C. Liu, C.C. Chen, J.H. Chen and C. Lin. Wat. Re 43, 5015 -5022 (2009).

[23] A. Hiskia and E. Papaconstantinou, Inorg. Chem 31, 163-167 (1992).

[24] A. Troupis, E. Gkika, T. Triantis, A. Hiskia and E. PapaconstantinouJ. Photochem. Photobiol. A: Chem 188, 272-278 (2007). 